\title{
LAS ASOCIACIONES DE MIGRANTES HAITIANOS EN EL ECUADOR: ENTRE DEBILIDAD Y RESISTENCIA
}

\author{
Mauricio Burbano Alarcón, S.J. ${ }^{1}$
}

\begin{abstract}
Las iniciativas asociativas haitianas en Ecuador hay que verlas dentro del contexto generado por el terremoto del año 2010 en Haití. Se trata de una población que se ha visto forzada a migrar, pero que no se la considera dentro de los parámetros de protección de acuerdo a la Convención sobre el Estatuto de los Refugiados de 1951, por lo que permanecen en situación de desprotección por su irregularidad migratoria. En este contexto, hay dos asociaciones haitianas en Quito que han jugado un importante rol especialmente en el ámbito de la asesoría y comunicación, tornándose en espacios de participación cívica. Al ser iniciativas asociativas débiles, peligran su existencia al contar con pocas redes de apoyo institucional.
\end{abstract}

Palabras clave: Ecuador, Haití, asociaciones, migración irregular, migración forzada.

\section{Introducción}

Según el Instituto Nacional de Estadísticas y Censos (INEC), el Ecuador en el año 2010 contaba con una población haitiana de 495 personas, de las cuales la mayoría (378) se encontraban en Quito. Según los datos de la Dirección Nacional de Migración sobre a las entradas y salidas de extranjeros (de nacionalidad haitiana), dentro del decenio 2004 - 2013 se contabilizaron 23.483 entradas y 7.233 salidas, dando un saldo positivo de 16.250 , de los cuales, el 95\% corresponde al periodo comprendido entre 2010 - 2013. Si bien son datos aproximados ${ }^{2}$ lo cierto es que nos muestran que a partir del terremoto

Doctorando en Ciencias Sociales, Universidad de Deusto, Bilbao, España.

2 No son datos "exactos" por cuanto el saldo positivo puede indicar tanto personas que se quedaron en el país como personas que salieron del país sin registrarse. Por otro lado, una misma persona puede generar más de una entrada/salida en el caso de que cruce las fronteras más de una vez. 
de 2010 la población haitiana que llegó (o pasó) por el país se ha incrementado significativamente.

Ecuador es un país de tránsito corto y tránsito largo para población haitiana. Según Gabriela Bernal³ ${ }^{3}$ las personas que vienen por tránsito corto generalmente están relacionadas con tráfico de migrantes (coyotes), por lo que su paso por Ecuador está dentro de las rutas para continuar su recorrido hacia el sur (Perú y Brasil). Los haitianos que vienen por tránsito largo ven al Ecuador como un posible destino para buscar oportunidades laborales y educativas. En cuanto al motivo de salida de Haití, hay que tomar en cuenta que el terremoto del 12 de enero de 2010 fue un detonante dentro de un contexto más amplio de inestabilidad social y política. Gabriela Bernal considera que hay diversos factores que influenciaron su salida y posterior Ilegada a Ecuador. Luego del terremoto del 12 de enero de 2010 los pobladores fueron a las zonas rurales para intentar reconstruir su vida, pero el Huracán Sandy (2012) provocó la destrucción de las cosechas (70\% según la OIT) e hizo que la gente se desplace nuevamente a las zonas urbanas. Sin embargo, vivir en el medio urbano no resolvió sus problemas, ya que se encontraron con ciudades destruidas y con un ambiente de violencia generalizada. En estas circunstancias, los haitianos que han salido para llegar al Ecuador, consideran que "en Haití ya no hay nada..." y por lo tanto se lanzan a un proceso emigratorio forzado.

En cuanto a los aspectos de género, la violencia sexual que ya se presentaba en Haití, hace que en el contexto familiar las mujeres jóvenes sean muy cuidadas o sobreprotegidas, por lo que es percibido como normal que el hombre controle y mantenga a la mujer en el espacio privado. Esto hace que en el espacio público de la ciudad de Quito sean más visibles los hombres, mientras las mujeres permanecen ocultas. Este hecho, en parte explicaría la escasa presencia de mujeres en las iniciativas asociativas haitianas.

En el ámbito legal ecuatoriano, la Constitución de la República del Ecuador define al país como un Estado "plurinacional e intercultural". La movilidad humana se incluye en el apartado de "derechos de las personas y grupos de atención prioritaria" (Cap. 3) según el cual no se considerará "a ningún ser humano como ilegal por su condición migratoria" (Art. 40) y se propugna el "principio de ciudadanía universal" (Art. 416). Como parte de la integración latinoamericana, se propicia "la creación de la ciudadanía latinoamericana y caribeña; la libre circulación de las personas en la región" (Art. 423). A partir de estos antecedentes constitucionales se comprende que por disposición del presidente Rafael Corea se estipulara que a partir del 20 de junio de 2008 no se necesitaría visa de turista

3 Antropóloga que investiga la migración haitiana en Ecuador (entrevista realizada el 27 de junio de 2013). 
para permanecer en Ecuador por un período de 90 días. Sin embargo, más adelante se retomarían medidas de restricción migratoria ${ }^{4}$. Parte del fracaso de la apertura de fronteras se debe a que no ha venido acompañada de procesos de integración social. El Ecuador todavía tiene vigente una Ley de Extranjería de los años setenta, elaborada en época de la dictadura, en donde imperaban políticas de seguridad y control. En este sentido, las políticas migratorias son contempladas desde el una visión legal-administrativa y no desde una perspectiva ciudadana que contemple como prioridad la integración social del inmigrante ${ }^{5}$. Subsiste una jerarquización de acceso a derechos de acuerdo al estatus migratorio, en cuya base más desprotegida se encuentra el migrante irregular.

Por otro lado, en Ecuador se presenta una opinión pública en la que se diferencia entre extranjeros aceptados y rechazados ${ }^{6}$. La población haitiana en Quito pasaría a formar parte de esos extranjeros rechazados o "no deseados"7. La irregularidad migratoria les condena a la exclusión económica (al conseguir empleos precarios) que se suma a la exclusión por rasgos étnicos (por ser población afrodescendiente). Con todo, a pesar de presentarse situaciones de rechazo y hasta de racismo ${ }^{8}$, los haitianos tienen una gran voluntad de integración ya que "presentan niveles favorables de relacionamiento con nacionales y participación en espacios sociales compartidos. Favorablemente, encuentran espacios donde pueden emprender el desafío de la integración lingüística ${ }^{9}$. Sin embargo, las principales razones por las que salieron de su país, trabajo y estudios, se ven truncadas por su posición jurídica irregular. Trabajo y estudios truncados además por la discriminación étnica de los quiteños y quiteñas"10.

${ }_{4}$ En diciembre de 2009 se exige visas a los chinos y en septiembre de 2010 a otras nueve naciones.

5 Cf. BURBANO, Mauricio. Movilidad Humana e Integración Social en Ecuador de acuerdo al 'Plan Nacional para El Buen Vivir 2009-2011'. Madrid: Instituto Universitario de Estudios sobre Migraciones - U. P. Comillas, 2012.

6 En Quito, los extranjeros más aceptados eran europeos y estadounidenses, mientras los más rechazados (opiniones negativas) eran los colombianos, peruanos y cubanos (año 2010). VERDESOTO, Luis; ZEPEDA, Beatriz. Ecuador, las Américas y el Mundo 2010: Opinión Pública y Política Exterior, p. 103-104.

7 MALO, Nicolás. Entre el drama y la integración: inmigrantes y refugiados haitianos en el Ecuador, p. 112.

8 Un haitiano que se encontraba caminando por un barrio quiteño del norte de la ciudad se encontró con que "la gente [del barrio] estaba llamando a la policía para llevarlo preso porque es un negro... iellos [los moradores] le tenían miedo!" (Hecho relatado por uno de los coordinadores de iniciativas asociativas).

9 La integración lingüística se realiza a partir de redes de amigos, redes eclesiales (católicas y evangélicas) y también mediante la Escuela de Español que ha llevado adelante el Servicio Jesuita a Refugiados (hasta julio de 2014). Actualmente los cursos de español están a cargo del Gobierno Autónomo Descentralizado de la Provincia de Pichincha.

${ }^{10}$ MALO, op. cit., p. 118. 


\section{Migración haitiana: ¿forzada o voluntaria?}

La migración forzada es un "término genérico que se utiliza para describir un movimiento de personas en el que se observa la coacción, incluyendo la amenaza a la vida y su subsistencia, bien sea por causas naturales o humanas"11. Desde esta definición genérica, se podría decir que la población haitiana que llegó al Ecuador después del terremoto del 12 de enero de 2010 se vio forzada a desplazarse debido a causas naturales. El gobierno de Ecuador, el 9 de febrero de 2010, expidió el Decreto Ejecutivo No 248 (firmado por el presidente Rafael Correa) en el que se manifestaba "que el pueblo de la República de Haití se encuentra atravesando una grave crisis humanitaria, económica y social como consecuencia del devastador terremoto...". Se abrió la posibilidad de regularización de ciudadanos y ciudadanas de nacionalidad haitiana que se encontraban en el Ecuador de forma irregular, con la condición de que hayan ingresado al país hasta el 31 de enero de $2010^{12}$. Sin embargo, la mayoría de haitianos llegaron posteriormente, quedándose sin oportunidad de regularizar su estatus migratorio. Por eso, dos años después del terremoto, los inmigrantes haitianos en Ecuador pidieron al gobierno poder legalizar su situación, puesto que sin papeles se ven expuestos a condiciones de abuso y explotación laboral ${ }^{13}$.

En la actualidad, los jóvenes haitianos que presentan un tránsito largo o con perspectivas de quedarse en Ecuador están en búsqueda de posibilidades laborales y educativas. Si se mira este dato de forma puntual, parecería que se trata de una migración plenamente libre en la que se busca mejorar las condiciones de vida para ellos mismos y sus familiares que quedaron en Haití. Desde una visión descontextualizada, que no toma en cuenta los fenómenos sociales desde una perspectiva histórica y procesual, la migración haitiana ya no sería migración forzada sino migración económica (voluntaria). La violencia de la naturaleza detonó otros tipos de violencia social en las que todavía no se encuentra caminos de solución definitiva, generando así una cadena de nuevos factores de desplazamiento forzado ${ }^{14}$. Además, el hecho de que haitianos y haitianas manifiesten su "deseo por escapar"15, nos muestra una suerte de

11 OIM. Glosario sobre Migración, p. 39.

${ }^{12}$ Esta regularización otorgaba sin costo alguno una visa de no inmigrante por tiempo de vigencia de 5 años.

${ }^{13}$ Cf. "Inmigrantes haitianos piden al Gobierno legalizar su residencia". Diario El Universo, 3 de abril de 2012. Disponible en: <http://www.eluniverso.com/2012/04/03/1/1360/inmigrantes-haitianospiden-gobierno-legalizar-residencia.html>. Consultado: 31/07/2014.

${ }^{14}$ Quienes han quedado en el país, luego de cuatro años del terremoto, no han visto mejoras significativas en sus vidas y se afrontan situaciones como personas viviendo en campamentos, problemas de insalubridad, falta de oportunidades laborales y educativas, violencia de género, hacinamiento carcelario, etc.

${ }^{15}$ BERNAL, Gabriela. La migración haitiana hacia Brasil: Ecuador, país de tránsito, p. 72. 
expulsión que no puede ser comparada con una migración libremente elegida. La niñez ${ }^{16}$ y juventud ${ }^{17}$, esperanza del país, encuentra grandes obstáculos a la hora de acceder en Haití a derechos tan básicos como la salud y educación. Vale la pena preguntarse: iLa migración es realmente voluntaria en las condiciones en que se encuentra la nación más pobre del hemisferio occidental ${ }^{18}$ ? La pobreza también puede verse como una "violencia" que genera desplazamiento, por eso la OIM define al "migrante por pobreza" como "individuo forzado a migrar por necesidades económicas"19. Cuando acechan el hambre y la violencia (política o de la naturaleza) los factores expulsores se complejizan ya que deja de haber "una" sola causa que motiva el desplazamiento, por lo que no siempre es posible distinguir entre "migración forzada" y "migración económica"20.

\section{El derecho a la asociación y la migración en Ecuador}

Independientemente del estatus migratorio, las iniciativas asociativas de migrantes constituyen un medio privilegiado de soporte a nivel personal del asociado y a nivel comunitario al estrechar relaciones entre ellos y tender puentes con la sociedad que los acoge. Con todo, para que dichas asociaciones se fortalezcan y pasen de la informalidad a la formalidad, es necesario que haya un contexto de acogida y apoyo a dichas iniciativas por parte del estado-nación receptor. En el Estado ecuatoriano, el derecho a la libre asociación tiene un largo recorrido que se refuerza por la firma de acuerdos internacionales como por ejemplo la Declaración Universal de los Derechos Humanos y la Convención Americana sobre Derechos Humanos (CADH) comúnmente conocida como "Pacto de San José" (firmado por Ecuador en 1969 y ratificado en 1977).

La Constitución de la República del Ecuador en su capítulo correspondiente a los "Derechos de libertad", reconoce "el derecho a asociarse, reunirse y manifestarse en forma libre y voluntaria" (Art. 66 n. 13). Como la Constitución requiere instrumentos legales de aplicación, en lo referente a la conformación de organizaciones y asociaciones civiles, se dispone de la "Ley

\footnotetext{
${ }^{16}$ Según la UNICEF, la situación de pobreza y deterioro del país hace que la infancia se encuentre en peligro y resulte "muy improbable que para 2015 Haití haya conquistado el objetivo de la educación universal". Cf. <http://www.unicef.org/spanish/childalert/haiti/overview.php>. Consultado: 16/08/2014.

17 “...ni las autoridades haitianas [...] ni la Comunidad internacional han logrado devolver a los jóvenes haitianos la esperanza de que el país se vaya a levantar luego del terremoto". LOUIDOR, Wooldy E. "¿Por qué se desespera la mayoría de los jóvenes haitianos?". Adital. Disponible en <goo.gl/eoQ3JW>. Consultado: 27/08/2014.

${ }^{18}$ Cf. Haiti Overview. Disponible en <http://www.worldbank.org/en/country/haiti/overview>. Consultado: 24.08.2014.

${ }^{19}$ OIM, op. cit., p. 43.

${ }^{20}$ Cf. HUJO, Katja; PIPER, Nicola (eds.). South-South Migration: Implications for Social Policy and Development; CASTLES, Stephen. Why Migration Policies Fail.
} 
Orgánica de Participación Ciudadana"21. Si se analiza dicha ley se observa que la participación ciudadana asume como base la pertenencia al estado-nación ecuatoriano aunque no necesariamente circunscrita o limitada al territorio nacional, ya que se incluye dentro de la participación a "las ecuatorianas y los ecuatorianos en el exterior", ampliando así su alcance a un nivel transnacional y posibilitando la participación en igualdad de condiciones de asociaciones de migrantes ecuatorianos. En otras palabras, el tema de movilidad humana y asociacionismo sí está contemplado pero únicamente en cuanto "asociaciones de ecuatorianos en el exterior" y no en la contraparte ecuatoriana que serían las asociaciones de migrantes extranjeros (en el Ecuador). Conjuntamente con esta Ley Orgánica, tiene actual vigencia el Decreto Ejecutivo 16 (del 4 de junio de 2013) según el cual se expide el Reglamento para el funcionamiento del Sistema Unificado de Información de las Organizaciones Sociales y Ciudadanas (SIUS). El reglamento es aplicable al ámbito de organizaciones sociales y ciudadanas así como entidades que promueven la participación y ONG's extranjeras que realizan actividades en el Ecuador. Sin embargo, no contempla un tratamiento especial para asociaciones de migrantes.

En materia de movilidad humana en Ecuador existe un desbalance por cuanto se la mira preferentemente en función de la "emigración ecuatoriana" sin considerar recíprocamente la inmigración de extranjeros desde una visión integral de derechos e integración social ${ }^{22}$. A pesar de esta dificultad, el deseo de asociarse de los extranjeros puede más que la falta de apoyo, y por eso en el Ecuador se puede encontrar iniciativas asociativas (formales y no formales) de carácter civil de distintos colectivos de inmigrantes: colombianos, peruanos, argentinos, cameruneses, brasileños, haitianos, etc. Se trata de asociaciones civiles que de acuerdo a sus propios objetivos y actividades generan bienes tangibles e intangibles que benefician no solamente a quienes participan de dichas agrupaciones, sino también al conjunto de la sociedad por cuanto fomentan la diversidad de expresiones socioculturales dentro de un Estado que se define como "plurinacional e intercultural".

\section{Las asociaciones de haitianos ${ }^{23}$}

Los haitianos en el Ecuador cuentan con dos iniciativas asociativas que se localizan en Quito. Esto se comprende porque en la ciudad vive una importante población haitiana ${ }^{24}$ y porque la capital dispone de una institucionalidad (no

\footnotetext{
${ }^{21}$ Aprobada por la Asamblea Nacional en el año 2010.

${ }^{22}$ Cf. BURBANO, op. cit.

${ }^{23}$ Los resultados presentados fueron recogidos entre julio y septiembre de 2013, a partir de una metodología cualitativa.

${ }^{24}$ Según el Censo de Población y Vivienda más de las tres cuartas partes de la población haitiana
} 
gubernamental y pública), que resulta de interés para las asociaciones. La primera asociación haitiana empezó a reunirse de manera informal en el año 2009 y estaba inicialmente compuesta por personas residentes en el Ecuador que vieron la necesidad de apoyar y orientar en su nuevo contexto a los nuevos haitianos recién llegados ${ }^{25}$. Surgió como una iniciativa apoyada en el contexto de una parroquia católica, pero con apertura a cualquier haitiano sin importar su credo o condición migratoria. Solamente más adelante se denominaría "Asociación de Haitianos Residentes y Refugiados del Ecuador (AHRRE)". Con este nombre, quieren identificarse por su condición migratoria. Si bien pocos de sus integrantes han sido reconocidos oficialmente como "refugiados", quieren identificarse como tales, hecho que se comprende porque, de manera general, los mismos haitianos "reclaman ser considerados como personas en una situación de migración forzosa" ${ }^{\prime 2}$.

La asociación AHRRE cuenta con aproximadamente 60 miembros de los cuales solamente el 30\% lo integran mujeres. Este hecho se puede comprender porque han ingresado al Ecuador un mayor número de hombres respecto a las mujeres haitianas, pero también puede deberse a la influencia de cuestiones socioculturales, puesto que generalmente es el hombre quien se muestra en el espacio público. Con todo, quien lidera la asociación es una mujer haitiana. Esto no se debe a que haya "sensibilización de género" sino más bien al hecho práctico de contar con una mujer líder con experiencia de diez años de vivir en el Ecuador, que ha participado de iniciativas asociativas tanto en Haití como en el país de acogida (con afroecuatorianos) y que domina el español, además de las dos lenguas oficiales de su país (francés y creole). Este "capital cultural" le permite ejercer una función mediadora entre el contexto haitiano y el ecuatoriano.

La segunda iniciativa asociativa de carácter informal surgió a fines del año 2011 y se denomina "Comunidad Haitiana del Ecuador". Cuenta con aproximadamente 50 miembros de los cuales el 90\% lo integran hombres. En cuanto a su estructura, además del presidente cuentan con promotores que se encuentran en distintos barrios donde hay población haitiana ${ }^{27}$. Al contrario de la primera asociación, ellos prefieren no identificarse por su condición

está en Quito. El hecho de que se concentren en la capital puede deberse a que el costo del pasaje es más barato y se han ido tejiendo redes migratorias en dicha ciudad, ya que en principio parecería más "natural" que el haitiano se asiente en zonas de la costa ecuatoriana y no en Quito cuyo clima, altura y composición étnica hace que sea "más difícil la mimetización con el entorno" (BERNAL, op. cit., p. 70).

${ }^{25}$ Su llegada se facilitó porque a partir del 20 de junio de 2008 no se necesitaba visa de turista para ingresar al Ecuador.

26 “[...] pues su país no les ofrece las condiciones mínimas de supervivencia, especialmente después del terremoto". BERNAL, op. cit., p. 76.

${ }^{27}$ Ubicados en el norte de la ciudad: Comité del Pueblo, La Ofelia, Colinas del Norte, Atucucho, La Planada, Conocoto y Chiriacu. 
migratoria y más bien expresamente se presentan como "comunidad" porque su objetivo es prestar un servicio a los haitianos en general, en un ambiente flexible de participación. Esta flexibilidad les ha llevado a estar disponibles para brindar asesoría a cualquier haitiano ya sea regular o irregular, y sin importar el credo religioso, como afirma uno de los promotores: “...todos los haitianos son bienvenidos. Porque todos los temas [que se tratan en las reuniones] son para todos los haitianos". El único límite que se imponen a esta apertura es la legalidad. Es decir, están abiertos a acoger y asesorar a cualquier haitiano, pero no hacen concesiones en el caso de personas que puedan estar involucradas en redes de tráfico ${ }^{28}$.

Las dos iniciativas asociativas tienen un perfil de miembros que corresponde mayoritariamente a hombres adultos que tienen capacitación técnica en distintos oficios como albañilería, carpintería, electricidad, etc. Los encuentros o reuniones se realizan preferentemente en lugares relativamente cercanos a la mayoría de los residentes, de tal manera que se pueda llegar caminando, evitándose gastos de transporte. Como las asociaciones de haitianos no cuentan con una sede propia, suelen reunirse en lugares públicos y en iglesias ${ }^{29}$ que también hacen la función de espacios de socialización. El hecho de que les acojan en sedes religiosas no significa que los miembros de estas asociaciones se vean obligados a pertenecer a dichas iglesias. En todo caso, esto nos muestra que los espacios "religiosos" no se ven como un obstáculo para sus fines de carácter "civil". Es más, como afirma Mark Warren, las iniciativas asociativas apoyadas por entidades religiosas pueden servir para desarrollar ciertos fines sociales deseables como proveer bienestar a aquellos que han quedado fuera de la red de protección oficial ${ }^{30}$.

En cuanto a las actividades desarrolladas, la "Asociación de Haitianos Residentes y Refugiados del Ecuador" (AHRRE) tiene un énfasis en las actividades culturales. Llevan adelante un grupo de danza, un grupo musical y ofrecen clases de francés a la comunidad ecuatoriana. También han participado de actividades deportivas (en el conocido parque quiteño de "La Carolina") y de espacios de formación en Ciudadanía y Derechos Humanos. La "Comunidad Haitiana del Ecuador" ha logrado fortalecer su actividad comunicativa gracias al apoyo de

${ }^{28}$ En una ocasión, uno de los promotores recibió una llamada telefónica desde Haití: "Tengo un primo mío que va a venir a Ecuador. Por favor puede ir a buscarle y darle hospedaje [...]". Le acogió solidariamente, pero más adelante se enteró que dicha persona no era pariente y había pagado (al coyote) por la visa y hasta por el hospedaje que el promotor daba gratuitamente en Quito. “Después cuando me llamó, le dije: 'iNo me haga eso! Usted cobra a los haitianos, ahora usted quiere involucrarme en eso. No me llame más, yo no voy a hacer nada por usted. Eso es un tráfico, es un delito'. [El coyote] se quedó callado y nunca más me llamó desde Haití".

${ }^{29}$ Se ha fortalecido la presencia de iglesias evangélicas.

30 WARREN, Mark. Democracy and Association, p. 37. 
la radio de la "Casa de la Cultura Ecuatoriana" que les ofrece un espacio de una hora cada semana. El programa radial es de carácter socioeducativo y se abordan temas relacionados con fechas emblemáticas (como el día del refugio, de los derechos humanos, de los niños, etc.). Inicialmente dicho programa era transmitido en creole pero los coordinadores vieron que era conveniente hacerlo en idioma español para que se abra la participación a funcionarios de diversas entidades públicas y no gubernamentales que trabajan de una u otra manera temas de migración. El programa denominado "Chita Tande" (que es una expresión del idioma creole y significa "sentarse y escuchar") se inspira en la experiencia inmigrante que para comprenderla se necesita "sentarse y escuchar" de parte y parte; es decir, de parte de la población ecuatoriana y de la población inmigrante. Cuentan además con un grupo activo de Facebook. Se puede afirmar que el servicio a los haitianos se centra de manera general en la "asesoría", que se lleva a cabo mediante llamadas telefónicas que reciben los coordinadores o promotores. Esta asesoría cumple una función comunicativa importante en el contexto de informalidad y desinformación en la que se mueve el inmigrante haitiano. No pocas veces los coordinadores tienen que disipar falsos rumores y dar información verídica a la población haitiana. Esta labor que puede ser aparentemente inocua juega un importante rol a la hora de evitar que los haitianos sean engañados y sus derechos violentados. En ese sentido, también cumplen una función educativa para que los haitianos puedan desenvolverse en la realidad ecuatoriana desde distintas facetas: trámites, normativas legales, derechos laborales, etc. También una función mediadora en cuanto a brindar informaciones útiles sobre dónde acudir en el caso de tener necesidades concretas en cuestiones de salud y vivienda ${ }^{31}$.

El financiamiento de las asociaciones haitianas es un tema crítico que constituye una constante amenaza para la continuidad de las mismas. Las asociaciones ofrecen asesoría gratuita, por lo que no cuentan con un presupuesto fijo que les permita planificar a largo plazo y ampliar su ámbito de actuación. Los miembros de las asociaciones que tienen actividades de responsabilidad desempeñan su trabajo de forma voluntaria, sin ninguna remuneración por su tiempo entregado. El compromiso personal de los coordinadores se manifiesta en que en ocasiones les toca poner dinero de su propio bolsillo. En medio de esta precariedad, para emprender sus actividades ha resultado fundamental la presencia de algunas redes de apoyo institucional (ONGs), de carácter cultural (Casa de la Cultura Ecuatoriana) y de carácter eclesial (católico y evangélico). Por otro lado, han visto cerradas la puerta de instituciones que se dedican a atender

${ }^{31}$ Los haitianos han sido atendidos en los hospitales públicos ecuatorianos (sin importar su estatus migratorio). En contraste "en razón del color de su piel, no les resulta fácil encontrar vivienda" (BERNAL, op. cit., p. 77). 
a migrantes forzados bajo una estrecha definición del "refugio". En este sentido, la red de apoyo de las asociaciones haitianas es más débil que las redes de apoyo de asociaciones de colombianos en situación de refugio en el Ecuador. Esta debilidad también influye para que no se genere ninguna actividad de carácter transnacional o de "codesarrollo" en su lugar de origen.

La situación de migración irregular de los haitianos evidentemente tiene consecuencias en sus procesos asociativos, presentándose un constante drenaje de su capital social. Esto impide el fortalecimiento de redes e impide el plantearse objetivos a más largo plazo. Con todo, las iniciativas asociativas siguen adelante gracias al compromiso de algunos coordinadores que tienen una experiencia como residentes de tres años o más en el Ecuador. A pesar de que las asociaciones tienden a la informalidad, se generan procesos de participación ciudadana $^{32}$ puesto que demuestran una voluntad de ser actores de sus propios procesos en el camino de integración social en el Ecuador. Se trata de una lucha contra corriente puesto que, si por un lado la irregularidad migratoria oficialmente les declara como excluidos del Estado-nación ecuatoriano, con sus procesos asociativos, se resisten y generan procesos ciudadanos. Si por un lado, la migración irregular provoca una invisibilidad que facilita la vulneración de sus derechos (por ejemplo, al ser objeto de explotación laboral); por otro lado, los procesos asociativos hacen un contrapeso al abrir canales visibles de comunicación y asesoría.

\section{Conclusiones}

Las asociaciones de haitianos en el Ecuador hay que verlas dentro del contexto amplio de la situación de vulnerabilidad del colectivo haitiano en general, por cuanto al estar en situación irregular no pueden cumplir sus expectativas de integración social en temas básicos como el trabajo y educación. La irregularidad migratoria les lleva a una situación precaria en la que ni siquiera pueden acceder a una cuenta bancaria, puesto que los bancos exigen un contrato de trabajo y para tener un trabajo se exige la regularidad migratoria, creándose así un círculo vicioso de exclusión. Así, los haitianos que tenían la expectativa de tener como destino final el Ecuador, al no encontrar caminos de regularización migratoria, no tener trabajo y ser discriminados, son forzados a continuar su tránsito migratorio en condiciones de gran vulnerabilidad. En este sentido, "al no haber una solución legal a su situación migratoria, se los empuja directamente a buscar las salidas irregulares, donde las redes de tráfico están presentes" ${ }^{\prime 33}$.

\footnotetext{
32 Ver nota 39.

33 BERNAL, op. cit., p. 79.
} 
La migración haitiana es un fenómeno social complejo que nos muestra la insuficiencia de las clásicas distinciones entre categorías migratorias ${ }^{34}$. Estas categorías buscan la eficacia en el control migratorio del estado-nación, pero resulta que ya no cumplen con el sentido original de ser un apoyo eficaz para las políticas migratorias. Como afirma Stephen Castles, estas distinciones están fracasando en el contexto de globalización debido a que las redes o cadenas migratorias una vez se han iniciado, continúan su curso incluso cuando las políticas migratorias han cambiado ${ }^{35}$. Es decir, no porque se aplique una política de restricción migratoria significa que dejarán de venir haitianos ${ }^{36}$. Simplemente estas personas seguirán llegando, y al no obtener un estatus migratorio que les proteja, se quedarán en una mayor vulnerabilidad como inmigrantes irregulares. En definitiva, el caso de la movilidad haitiana pone a prueba tanto las viejas categorizaciones migratorias como la solidaridad de la comunidad internacional. Es una población que requiere protección internacional, pero no entra en los parámetros de la Convención sobre el Estatuto de los Refugiados de 1951; con todo, la protección a los haitianos podría basarse en la Declaración de Cartagena sobre los Refugiados de 1984.

Las dos iniciativas asociativas (AHRRE y Comunidad Haitiana) subsisten en condiciones difíciles por la precariedad de medios y recursos. Estas agrupaciones vienen a ser iniciativas asociativas de "resistencia" ${ }^{37}$ por cuanto su supervivencia se realiza a pesar de tener un contexto adverso tanto al interior como hacia al exterior. Hacia el interior, presentan debilidad por cuanto no tienen sede propia, son asociaciones jóvenes (escasa experiencia) y no cuentan con un presupuesto fijo. En cuanto al exterior, las asociaciones haitianas cuentan con una reducida red de apoyo institucional. Esto se debe a que las instituciones que apoyan a los "migrantes forzados" se concentran especialmente en aquellos que cumplen con los parámetros clásicos del refugio ${ }^{38}$. A pesar de este contexto adverso, las asociaciones de haitianos han demostrado una gran iniciativa a la hora de atender a las demandas de asesoría de dicha población. Es el único colectivo de migrantes en Quito que cuenta con su propio programa radial (facilitado por la Radio



${ }^{35}$ Cf. CASTLES, Stephen. Ethnicity and Globalization, p. 80-81.

${ }^{36}$ Esto sucede en la frontera entre Ecuador y Perú (país que exige visa a los haitianos desde 2012). Esta medida ha hecho que disminuya el número oficial de salidas de Ecuador (de 14099 entradas, solo se registraron 1222 salidas en 2013). De ninguna manera significa un éxito de las políticas migratorias restrictivas, sino más bien es un indicio de una mayor actividad de las redes de tráfico que ofrecen a los migrantes otras vías de acceso.

${ }^{37}$ Cf. FUNG, Archon. Associations and Democracy: Between Theories, Hopes, and Realities.

${ }^{38}$ Hecho que corrobora la insuficiencia de las categorizaciones migratorias clásicas ya que "la mayoría de los migrantes forzados huyen por razones que no son reconocidas por el régimen internacional de refugiados" (CASTLES, Stephen. La política internacional de la migración forzada, p. 3). 
de la Casa de la Cultura), espacio que no tienen otros colectivos de migrantes con una presencia numérica mayor. La asesoría, si bien se ha mantenido en un ámbito informal (debido a la precariedad de recursos), ha jugado un importante papel mediador de cara a sus coterráneos, especialmente cuando el Ecuador no contaba con una representación consular haitiana, ya que solamente a partir de mediados del año 2013 se dispone de embajada y consulado de Haití. A pesar de su precariedad, estas asociaciones por medio de sus acciones han motivado procesos de participación desde un marco amplio de ciudadanía ${ }^{39}$.

El tema de la integración social del migrante extranjero no pocas veces se aborda desde perspectivas folcloristas (como algunos "festivales interculturales") sin incorporar una visión integral de derechos. El fomento de iniciativas asociativas a partir de acciones afirmativas es una vía posible para esa incorporación del migrante a partir del derecho a la asociación y participación. De manera general el tejido asociativo surge a partir de iniciativas informales y débiles, por lo que para su consolidación se requiere apoyos externos, donde juegan un importante papel las ONGs y las subvenciones estatales y municipales. Esto no es nada nuevo, por cuanto las mismas asociaciones de ecuatorianos en el exterior se han beneficiado de subvenciones por parte de los estados receptores ${ }^{40}$. En el caso de Ecuador, las asociaciones de migrantes extranjeros no cuentan con una normativa que les permita acceder a subvenciones que promuevan su inserción social. En este sentido, es urgente que el Estado ecuatoriano apoye decididamente los procesos organizativos de los diversos colectivos migrantes. Por otro lado, en el caso de la ciudad capital, tanto el "Gobierno Autónomo Descentralizado de la Provincia de Pichincha" como el "Municipio del Distrito Metropolitano de Quito"41 tienen el reto de atender las demandas producidas por la movilidad humana con sus procesos de migración interna, retorno, emigración e inmigración internacional. El apoyo a las diversas iniciativas asociativas seguramente redundará en la convivencia social en la diversidad, por cuanto es uno de los medios privilegiados para mejorar las normas colectivas, fomentar la confianza y prevenir el racismo y xenofobia.

${ }^{39}$ La ciudadana generalmente se asocia como un derecho adquirido por quienes pertenecen a un determinado estado-nación. Sin embargo, también puede referirse a la participación de personas (migrantes o no) en contextos locales que implican vecindad, participación en espacios asociativos, ejercicio de derechos, obligaciones, etc. Es decir, la ciudadanía como participación en el ámbito local tiene que ver con aspectos cívicos que vienen a recrear una cultura pública. Cf. TORRES, Francisco. La inserción urbana de los inmigrantes y su participación en la ciudad.

${ }^{40}$ En España se mantienen iniciativas de promoción de asociaciones de inmigrantes apoyadas por los ayuntamientos, más allá de que se trate de inmigrantes con estatus regular o irregular. Cf. < http:// www.murcia.es/ServiciosSociales/info_sectores.asp?sector=5>. Consultado: 20/04/2014.

${ }^{41}$ El Distrito Metropolitano de Quito tiene la mayor concentración de migrantes del Ecuador. Según el INEC (Censo de Población y Vivienda), de los 1.619.146 habitantes, el 35,5\% nacieron en otro lugar del país, y el 2,7\% nacieron en otro país. 


\section{Bibliografía}

ASAMBLEA CONSTITUYENTE. Constitución de la República del Ecuador. Montecristi: Asamblea Constituyente de la República del Ecuador, 2008.

ASAMBLEA NACIONAL. Ley Orgánica de Participación Ciudadana. Quito: Registro Oficial del Ecuador (n. 175), 20 de Abril del 2010.

BERNAL, Gabriela. La migración haitiana hacia Brasil: Ecuador, país de tránsito. In OIM. La migración haitiana hacia Brasil: características, oportunidades y desafíos. Buenos Aires: OIM - Oficina Regional para América del Sur, 2014, p. 67-82.

CASTLES, Stephen. Ethnicity and Globalization. London: Sage, 2000.

CASTLES, Stephen. La política internacional de la migración forzada. Migración y Desarrollo, n. 1. Octubre 2003, p. 1-28.

CASTLES, Stephen. Why Migration Policies Fail. Ethnic and Racial Studies, v. 27, n. 2, 2004, p. 205-227.

DIRECCIÓN NACIONAL DE MIGRACIÓN - INEC. Anuarios de Entradas y Salidas Internacionales. 2004-2013. Disponible en: <http://www.ecuadorencifras.gob. ec/entrada-y-salidas-internacionales/>. Consultado: 15/08/2014.

FUNG, Archon. Associations and Democracy: Between Theories, Hopes, and Realities. Annual Review of Sociology, v. 29, 2003, p. 515-539.

HUJO, Katja; PIPER, Nicola (eds.). South-South Migration: Implications for Social Policy and Development. Basingstoke: Palgrave Macmillan, 2010.

INEC. Censo de Población y Vivienda. Quito: Instituto Nacional de Estadística y Censos, 2010. Disponible en: <http://www.inec.gob.ec/estadisticas/>. Consultado: 03/04/2014.

MALO, Nicolás. Entre el drama y la integración: inmigrantes y refugiados haitianos en el Ecuador. [Trabajo de grado]. Quito: PUCE, 2013.

OIM. Glosario sobre Migración. Ginebra: Organización Internacional para las Migraciones, 2006.

TORRES, Francisco. La inserción urbana de los inmigrantes y su participación en la ciudad. In SIMÓ, Carles; TORRES, Francisco (eds.). La participación de los inmigrantes en el ámbito local. Valencia: Tirant lo Blanch, 2006, p. 91-131.

VERDESOTO, Luis; ZEPEDA, Beatriz. Ecuador, las Américas y el Mundo 2010: Opinión Pública y Política Exterior. Quito: FLACSO, 2011.

WARREN, Mark. Democracy and Association. Princeton, NJ: Princeton University Press, 2001.

\section{Abstract}

\section{Associations of Haitian migrants in Ecuador: between weakness and strength}

The Haitian associative initiatives in Ecuador have to be seen within the context generated by the 2010 earthquake in Haiti. This is a population that has been forced to migrate, but it is not considered within the 
parameters of protection under the Convention Relating to the Status of Refugees (1951), so they are left in lack of protection due to their irregular migration. In this context, two Haitian associations in Quito have played an important role especially in the field of counseling and communication, becoming spaces for civic engagement. Being weak associative initiatives, their existence is at risk by having scarce institutional support networks.

Keywords: Ecuador, Haiti, associations, irregular migration, forced migration.

Recebido para publicación en 27/08/2014.

Aceptado para publicación en 03/12/2014.

Received for publication in August, 27 ${ }^{\text {th }}, 2014$. Accepted for publication in December, 03 ${ }^{\text {th }}, 2014$.

ISSN impresso: 1980-8585

ISSN eletrônico: 2237-9843

www. http://dx.doi.org/10.1590/1980-85852503880004413 